\title{
CASIDA DE UN MORISCO ANÓNIMO PARA EL SULTÁN OTOMANO
}

\author{
Hany El Erian El Bassal*
}

A la memoria de Mikel de Epalza

Recoge el gran erudito tlemcení del siglo XVII al-Maqqarī en su libro Azhār al-riyād fi ajbār 'iyā $d^{1}$, que los musulmanes de la Península Ibérica después de la caída de Granada a manos de los Reyes Católicos y alrededor del año 1501 según James T. Monroe ${ }^{2}$ (1512 según López de Coca) ${ }^{3}$ enviaron una casida, compuesta por 105 versos de un autor desconocido y presidida por un prólogo, al sultán otomano Bayazid II en la cual le piden su socorro y auxilio. Van Koningsveld y Wiegers ${ }^{4}$ encontraron una versión más corta de la casida en una antología literaria marroquí elaborada entre los siglos XVII y XVIII, que fue enviada según ellos al sultán mameluco en Egipto a principios de 1500 y que fue adaptada un año más tarde a su nuevo destinatario, el sultán otomano citado por al-Maqqarī en la introducción del poema ${ }^{5}$.

Expone el poeta andalusí en su poema la difícil situación de los musulmanes que residen en al-Andalus, sometidos a los monarcas cristianos que violaron los pactos firmados entre musulmanes y cristianos después de la derrota de los primeros y que obligaron a los seguidores del Islam a convertirse al Cristianismo. Le explica al sultán otomano que se sienten extraños en su pro-

* Universidad de Alicante.

1. Šihāb ad-Dīn Āḥmad Ibn Muhammad Al-MAQQAR̄̄ AL-TILMISĀNĪ, Azhār al-riyāẹ fĩ ajbār 'iyāẹ, ed. por M. Al-AQQĀ, I. Al-ABYĀRĪ y 'A. ŠALABĪ, El Cairo, 1939.

2. Véase James T. Monroe, «A Curious Morisco Appeal to the ottoman Empire», Al-Andalus, XXI, 1 y 2, 1966, pp. 281-303.

3. Véase J.E. LÓPEZ DE COCA CASTAÑER, «El Islam y la caída de Granada», en La Península Ibérica en la era de los descubrimientos 1391-1492. Actas III Jornadas Hispano-portuguesas de Historia Medieval, Sevilla, 1997, pp. 1570-1571; Id., "Granada y los turcos otomanos, 1439-1516», Sardegna, Mediterráneo e Atlántico tra Medioevo ed Età Moderna: Studi Storici in Memoria di Alberto Boscolo, Roma, 1993, pp. 185-199.

4. P.S. VAN Koningsveld y G.A. Wiegers, «An Appeal of the Moriscos to the Mamluk sultan and its counterpart to the ottoman court: textual analysis, context and wider historical background», Al-Qanțara, XX, 1, 1999, pp. 165-178.

5. Al-MAQQARI , op. cit., p. 109. 
pio país, donde nacieron sus padres, abuelos y bisabuelos. Que fueron derrotados por los cristianos porque eran muchos más que ellos, y que no pudieron resistir a las embestidas de los ejércitos cristianos durante mucho tiempo; que lucharon contra ellos con todas sus fuerzas y que pidieron ayuda a todos los musulmanes de la tierra, pero esta ayuda nunca llegó. También relata el poeta que ellos representaban al Islam en al-Andalus y que lucharon por esta religión, y que hicieron la Guerra Santa contra los enemigos del Islam, religión que profesan tanto andalusís como otomanos. Califica a los cristianos de traidores, que no cumplen lo pactado, que prometieron a los musulmanes de Granada vivir como vivían los mudéjares que habitaban en los reinos cristianos durante siglos, que podían seguir practicando sus oraciones, hacer el Ramadán, conservar sus mezquitas, sus hogares, sus riquezas, y que sus mujeres se vistieran como manda la tradición islámica, que los hijos se educaran en el Islam. Igualmente los musulmanes podrían conservar los libros que tratan la fe de Muhammad y cómo no el sagrado Corán, y que sus mayores serían venerados como se venía haciendo durante siglos, que el honor de las chicas musulmanas sería respetado, que podrían comer carne halāl sacrificada según el rito islámico, que los muertos serían enterrados en cementerios musulmanes y practicado sobre ellos las oraciones que manda el Islam, que podrían viajar cuando quisieran a la otra orilla del Mediterráneo llevando con ellos todas sus riquezas, y finalmente que los Reyes Católicos garantizarían el cumplimiento de todo lo pactado y firmado, dándoles tanto su perdón como la protección.

Resalta el autor del poema que una vez que los musulmanes de Granada aceptaron las condiciones -después de haber sufrido el asedio de las tropas cristianas durante meses, y por miedo a que sus hijos e hijas fueran cautivados o asesinados- fueron engañados por los cristianos, que quebrantaron lo pactado, convirtieron las mezquitas en iglesias, sustituyendo la llamada a la oración por el almuédano por campanas, requisaron las casas de los musulmanes y sus bienes, les prohibieron practicar sus oraciones y les impidieron hacer el Ramadán -obligándolos a comer durante el periodo de ayuno-y si llegaba a los oídos de los cristianos que uno rezaba o ayunaba, acababan con él en la hoguera.

De la misma forma les prohibieron que sus mujeres llevasen el velo tradicional, les quemaron el Corán y los libros del Islam, les obligaron a comer cerdo y carnes no halāl, y a que los hijos acudieran a las iglesias y no se educasen en el Islam. Los muertos musulmanes fueron abandonados como los animales, sin poder hacerles entierros dignos como manda el Islam. Les obligaban a calumniar al Profeta y les prohibían implorarle, y si alguien utilizaba su nombre en la felicidad o en la desgracia era juzgado y condenado.

Pero no solo les obligaron a cambiar su religión, sino que también sus nombres fueron cambiados por nombres cristianos a su pesar, y fueron tratados y convertidos en esclavos, ni siquiera cautivos que pudieran ser rescatados. Una vez explicado por el autor de la casida al sultán otomano lo que han padecido y lo que están sufriendo, empieza a implorarle por Allah, por el Profeta, así como por la familia y amigos del profeta del Islam que les ayude a salir 
de esta situación y le aclara que los musulmanes de al-Andalus están dispuestos a llevar a cabo todo lo que mande y ordene el sultán de los turcos. A continuación recuerdan al sultán que los lugares más santos del cristianismo están bajo su dominio y en este punto debemos recordar que, tal como citamos anteriormente, esta carta fue enviada según Monroe, así como Van Koningsveld y Wiegers, a Bayazid II en el año 1501, pero Jerusalén fue conquistada por los otomanos un año antes de la conquista de Egipto en 1517 en época de Selim I, por lo que nos resulta extraño que el autor del poema se dirija al sultán otomano como dominador de los santos lugares de Jerusalén, cuando estos lugares estaban gobernados en aquel año y hasta 1516 por el sultán mameluco. Van Koningsveld y Wiegers opinan al respecto que se deben interpretar los versos que se refieren a los santos lugares en un sentido más amplio, apuntado a Constantinopla y los territorios cristianos del Imperio Bizantino de Asia Menor ${ }^{6}$ y no solo a Jerusalén. En cambio López de Coca Castañer prefiere pensar que era un despiste de quien redactó la segunda versión del poema, copiándose de la primera versión un verso que no debería copiar ${ }^{7}$. Por nuestra parte, pensamos que podría ser una equivocación o desconocimiento del propio autor de la carta del nombre del sultán de los otomanos en aquel momento o incluso un simple error del mismo al-Maqqarī, quien cita la carta un siglo después de enviarla, por lo que podría haber sido dirigida al sultán Selim I (1512-1520), sucesor de Bayazid II, por lo que en nuestra opinión la carta fue enviada alrededor del 1517 después de la conquista de Jerusalén y Egipto por parte de los otomanos.

El autor del poema se dirige al sultán otomano y le pide en nombre del Islam que amenace a los Reyes Católicos de que va a tomar represalias contra los lugares santos y los cristianos que viven en su reino, y si no le hacen caso, le impele a que hable con el papa de Roma para que convenza a los reyes de España de no seguir con la persecución de los musulmanes en al-Andalus, recordándole al mismo tiempo que durante siglos los reyes musulmanes en alAndalus no obligaron a los cristianos que vivían bajo su protección de renunciar ni a su fe ni a sus hogares.

El poeta informa al califa otomano que anteriormente Egipto mandó unos embajadores a España para verificar el estado de los musulmanes que vivían bajo el mando de los cristianos, pero los Reyes Católicos aseguraron a los enviados egipcios que los moriscos han cambiado el Islam por el cristianismo voluntariamente, sin ninguna coacción ni imposición. Pero el poeta afirma que las declaraciones de los testigos que presentaron a los egipcios eran falsas, y que nunca habían querido decir lo que dijeron, pero el miedo a las hogueras y a la

6. P.S. VAN KONINGSVELD y G.A. WIEGERS, op. cit., pp. 165-178.

7. J.E. LÓPEZ DE COCA CASTAÑER, «Reacción del mundo islámico ante la caída del Reino de Granada», http: / / www.alyamiah.com/ cema2 / index.php?option=com_content\&view=article $\& \mathrm{id}=633 \% 3$ Areaccion-del-mundo-islamico-ante-la-caida-del-reino-de-granada-\&catid $=47 \% 3$ Apensamiento-s-xvi-xvii\&Itemid $=50>$ [Consulta: 30 noviembre 2011]. 
muerte les llevó a aparentar que se habían convertido y a repetir las palabras que los cristianos les ordenaron decir, pero ellos en realidad solo creen en el único dios que es Allāh y nunca cambiarán su religión voluntariamente por una religión que afirma la Trinidad. Y si los cristianos anuncian que los andalusíes han aceptado su religión sin coacción, pues que pregunte a los habitantes de Güéjar, Velefique, Andarax o a la gente de las Alpujarras, que fueron despedazados a espada, aniquilados y quemados en las mezquitas.

Finalmente el autor de la casida plantea la pregunta ¿No hubiera sido mejor dejarnos con nuestra religión y nuestras oraciones, y si no, que nos hubiesen dejado irnos a todos de su tierra? Para ellos era mejor dejar sus tierras, sus casas y emigrar con honor siendo musulmanes a quedarse en la tierra de los cristianos y convertirse al cristianismo.

A continuación presentamos la traducción del árabe al castellano de la casida citada anteriormente, que se encuentra en el primer tomo del libro de al-

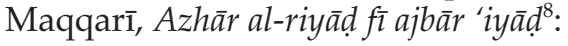

“Su Alteza, que Allāh aumente vuestra felicidad, que alce vuestras palabras en lo más alto, que allane vuestro reino, que atesore a vuestros seguidores y que humille a vuestros enemigos. Nuestro Señor, el sostén de nuestra vida y nuestra fe, el Sultán, el Rey y el Vencedor. Defensor de la vida y de la religión, Sultán del Islam y los musulmanes, subyugador de los enemigos de Allāh, mina del Islam, valedor de la religión de nuestro profeta Muhammad (la paz sea con él), restaurador de la justicia, justo con los oprimidos y con los opresores, rey de los árabes, los persas, los turcos y los dailamíes ${ }^{9}$, la sombra de Allāh en su tierra, el que cumple con su sunna y sus preceptos, rey de las dos orillas y sultán de los dos mares, protector del honor, represor de los infieles, nuestro señor, nuestro alcalde, nuestra mina y nuestro socorro, Nuestro Señor Abū Yazīd; su reino está lleno de incondicionales, acompañados siempre con la victoria, inmortalizado por sus batallas y conquistas, conocido por su magnificencia y su orgullo. Hace mucho el bien para aumentar su recompensa y ganar la otra vida y embellecer la presente. No abandonó su gran propósito por seguir la yihad con la intención de despojar a los enemigos del Islam de la maldad. Lo que apagaba la sed y apaciguaba a los de tez morena, las espadas, y las puntas de las lanzas. Eliminó las admirables municiones que se encuentran en las tierras donde se han acostumbrado las buenas almas abandonara a los cuerpos, tomando el camino de sus antepasados que ganaron la aprobación de Dios el día del Juicio Final".

1. La noble paz, eterna y renovada para mi Señor, el mejor de los Califas.

2. La paz sea sobre mi Señor, el más glorioso, que hizo vestir a los infieles el vestido de la humillación.

3. La paz sea sobre aquél al que Dios le ayudó a extender su reino y le otorgó la victoria en todos los lugares.

8. Al-MAQQARI , op. cit., pp. 109-116.

9. Los dailamíes eran un pueblo que habitaba las regiones montañosas del norte de Irán en la orilla sur del mar Caspio. 
4. La paz sea a mi Señor, que tiene la capital de su reino en Constantinopla, la más noble ciudad.

5. La paz sea con aquel cuyo reino lo engalanó Allāh con ejércitos y ciudadanos turcos de su confianza.

6. ¡La paz sea contigo! Que Allāh enaltezca vuestra posición y que vuestro reino se extienda sobre todos los cultos.

7. La paz sea con el juez y con quien quiera que sea como él de los nobles y grandes sabios.

8. La paz sea con los hombres píos y de fe, y con aquellos consejeros sabios y sensatos.

9. La paz sea contigo en nombre de hombres que permanecieron en Occidente -en al-Andalus-en sus tierras como extraños.

10. Rodeados de un mar lleno de $R \bar{u} m^{10}$ y de otro mar abismal, profundo y tenebroso.

11. La paz sea contigo en nombre de unos esclavos afligidos por una enorme desgracia, iy qué grande ha sido!

12. La paz sea contigo en nombre de unos ancianos cuyos blancos cabellos fueron arrancados, después de haber conocido el respeto.

13. La paz sea contigo en nombre de unos rostros obligados a descubrirse a los cristianos ${ }^{11}$, tras haber permanecido velados.

14. La paz sea contigo en nombre de unas doncellas humilladas a quienes el cura $^{12}$ arrastra por los cabellos y las golpea para estar a solas con ellas.

15. La paz sea contigo en nombre de ancianas obligadas a comer cerdo y carne que no es halāl.

16. Todos nosotros besamos el suelo que vos pisáis e imploramos a Dios que os otorgue todas las bondades siempre.

17. Que Allāh prolongue vuestro reinado y vuestra vida y os proteja de todo mal y de toda desgracia.

18. Y que Allāh os provea con la victoria y el triunfo sobre el enemigo, y os aloje en un paraíso lleno de complacencia y generosidad.

19. Nos quejamos ante ti, mi Señor, del perjuicio, la desgracia, y la enorme angustia que nos ha tocado vivir.

10. El autor utiliza el término "Rūm" como una forma muy recurrente entre los autores musulmanes para distinguir a los cristianos europeos. Sobre los términos utilizados por los musulmanes para llamar a los cristianos véase E. LAPIEDRA GuTIÉRREZ, Cómo los musulmanes llamaban a los cristianos hispánicos, Valencia, 1997, pp. 114-136.

11. El vocablo 'ily se puede traducir como bárbaro no musulmán, incivilizados e incluso cristianos. En el siglo XV se utilizó como un término despectivo para los que, a pesar de musulmanes, no son árabes. Sobre los términos de 'ilŷ, 'ulūŷy y a'lāŷ, véase E. LAPIEDRA GUTIÉRREZ, op. cit., pp. 245-247.

12. Hemos traducido la palabra al-labbāt como cura, que es lo más cercano a lo que nos indican los editores del libro Azhār al-riyāed, cuando los describen como hombres encargados por la iglesia para obligar a los musulmanes a abrazar al cristianismo, véase Azhār al-riyāẹ, p. 110, nota 2. 
20. Hemos sido traicionados y convertidos al cristianismo por la fuerza, cambiando nuestra religión por otra, y hemos sido maltratados y tratados con todo deshonor.

21. Hemos sido seguidores de la religión del profeta Muhammad, hemos combatido a los seguidores de la cruz con toda nuestra fuerza e intención.

22. Hemos hecho la Guerra Santa con todo lo que hemos podido, sufriendo hambre y sed, y corriendo el peligro de ser muertos o prisioneros.

23. Los cristianos nos atacaron por todos lados, un gran torrente de tropas y ejércitos.

24. Nos embistieron como si fueran unas bandadas de langostas prevenidas con caballos y armas.

25. Nos resistimos con proeza a sus ejércitos durante mucho tiempo, matando un grupo tras de otro.

26. Sus caballerías crecían cada momento mientras que la nuestra disminuía y escaseaba.

27. Cuando nos debilitamos, acamparon en nuestro país y atacaron nuestras ciudades una tras de otra.

28. Vinieron con grandes cañones que demolían las inaccesibles murallas.

29. Asediaron con fuerza, celo y obstinación las murallas durante meses.

30. Cuando aniquilaron nuestra caballería e infantería, y no recibimos de nuestros hermanos ninguna ayuda.

31. Y cuando nuestras vituallas habían disminuido y nuestra situación era realmente dura, y por miedo a más calamidad, nos plegamos a sus demandas.

32. Nos plegamos por temor a que nuestros hijos e hijas fueran cautivados o cruelmente asesinados.

33. Y con la condición de permanecer en situación semejante a la de los anteriores mudéjares, que habitaban el antiguo territorio.

34. Y que se nos permitiría seguir con nuestra llamada a la oración y nuestras plegarias, y sin renunciar a nada de nuestra ley religiosa.

35. Y a quien quiera de nosotros irse cruzando el mar, podría hacerlo en paz llevando con él lo que quisiera de su riqueza hacia las tierras de la otra orilla del Mediterráneo.

36. Aparte de esto, otras muchas condiciones que superan las cincuenta por cinco.

37. Nos dijo entonces su sultán, que es su máxima autoridad: os garantizo el cumplimiento de todo lo estipulado.

38. Y nos mostró documentos que contienen pactos y tratados y nos dijo: aquí tenéis mi perdón y mi protección.

39. Pues quedaos con vuestras posesiones y vuestros hogares, tal como estabais antes, pero desarmados.

40. Sin embargo, cuando aceptamos el pacto y quedamos bajo su protección, se hizo aparente su traición y rompieron lo pactado. 
41. Infringieron los pactos firmados con que nos habían engañado y nos convirtieron a pesar nuestro, por la fuerza, con dureza y severidad al cristianismo.

42. Quemaron los libros sagrados del Corán que teníamos y los mezclaron con basuras e inmundicias.

43. Todos los libros que trataban de asuntos de nuestra religión fueron presa del fuego entre la burla y el desprecio.

44. No dejaron ni un solo libro que perteneciera a un musulmán, ni un solo Corán en quien uno pudiera refugiarse leyéndolo en soledad.

45. Y si les llegaba a sus oídos que uno rezaba o ayunaba, acababan con él en la hoguera.

46. Y quien de nosotros dejaba de ir a los lugares de sus cultos era duramente castigado por el cura de turno.

47. Le abofeteaba en ambas mejillas, le confiscaba su dinero y posesiones, y le arrojaba en prisión en el mejor de los casos.

48. Y en el mes de Ramadán nos hacen interrumpir el ayuno obligándonos a comer y beber una vez detrás de otra.

49. Y nos ordenaban calumniar a nuestro Profeta y nos prohibían implorarle en tiempos de felicidad o desgracia.

50. Un día escucharon a unas personas cantando su nombre y fueron condenadas a sufrir.

51. Fueron juzgadas por sus jueces y gobernadores a ser castigados con azotes, multas, presión y humillación.

52. Y aquél al que le llegaba la muerte y no le atendía ningún cura, se negaban a enterrarlo.

53. Lo dejaban en la basura tirado, como si fuera un burro o un animal muerto.

54. Además de esto cometían otras muchas maldades y actos infamantes.

55. Nuestros nombres fueron cambiados y transformados en otros nombres sin nuestro consentimiento y sin haberlo deseado.

56. ¡Ay! pues nos cambiaron la religión de Muhammad por la de los perros cristianos, la peor raza de la tierra.

57. Y ¡ay! nuestros nombres que fueron cambiados por los nombres de bárbaros e ignorantes.

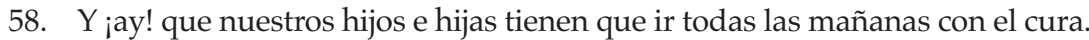

59. Les enseña idolatría, descreencia, y falsedades sin que ellos puedan negarse.

60. Y ¡ ay! de las mezquitas que fueron tapiadas y transformadas en basureros de los infieles después de haber conocido la pureza.

61. Y ¡ay! de aquellos alminares en los que cuelgan las campanas sustituyendo a la shahāda.

62. Y ¡ay! de aquellas ciudades y de su belleza, cómo se han oscurecido en la oscuridad de la incredulidad.

63. Y se han convertido para los adoradores de la cruz en fortalezas, y en ellas están a salvo de todo ataque. 
64. Y nos hemos convertido en esclavos, ni siquiera cautivos que puedan ser rescatados, y tampoco en musulmanes que pronuncian su shahāda.

65. Si vuestros ojos vieran nuestra situación, se inundarían en lágrimas.

66. ¡Ay! ¡Pobres de nosotros! ¡Qué desgracia que nos ha tocado! ¡Cuánto deshonor, cuánto sufrimiento y cuánta opresión!

67. Te invocamos, Señor, por nuestro dios Allāh y por el Elegido, el mejor hombre que ha conocido la tierra.

68. Y te pedimos por los más ilustres hombres, que son la familia de Muhammad y sus compañeros iqué nobles compañeros son!

69. Y te imploramos por nuestro señor al-'Abbās, tío de nuestro Profeta y por las canas de su cabellera, las más honorables canas.

70. Y te rogamos por los virtuosos reconocedores de su Señor y todos los hombres probos dotados de nobleza.

71. Tal vez miréis por nosotros y por lo que nos ha sucedido, quizá Allāh desde su Trono nos alcanza con su compasión.

72. Pues todo lo que vos indicáis es escuchado y todo lo que vos ordenáis es realizado y cualquier cosa que vos mandéis, rápidamente se llevará a cabo.

73. Pues el lugar de origen de la religión de los cristianos está bajo vuestra potestad y de allí se extendió a todos los territorios.

74. Por Allāh Señor nuestro, ¡dígnanos con el favor de aconsejarnos con un buen consejo o con acertados argumentos!

75. Vosotros sois los poseedores de la excelencia, la gloria y la más alta categoría, y sois los salvadores de los siervos de Allāh de todo mal.

76. Pregunta a su Papa, al que reside en Roma, ¿por qué permiten la traición después de haber firmado un tratado de paz?

77. $\mathrm{Y}$ ¿por qué nos atacaron y nos engañaron sin haber incurrido en incorrección ni tampoco haber cometido algún crimen?

78. Cuando su pueblo estuvo bajo la protección de nuestra religión después de haber sido conquistado por nuestros célebres reyes que siempre cumplían sus promesas.

79. No fueron obligados a renunciar a su fe ni a sus hogares y tampoco sufrieron la traición ni el deshonor.

80. Y quien firma un pacto y luego lo traiciona, eso es un hecho prohibido por todas las religiones.

81. Especialmente para los reyes, es un acto deshonroso y vergonzoso, prohibido por la ley en todas las naciones.

82. A ellos les llegó vuestro escrito, pero no tomaron en consideración ni una sola palabra de él.

83. No hizo más que aumentar sus hostilidades y sus atrevimientos en contra nuestra, así como sus persistencias en toda clase de maldades.

84. Y cuando los enviados de Egipto llegaron y no fueron tratados con traición ni con deshonor.

85. Y dijeron a estos enviados que habíamos aceptado voluntariamente la religión de los incrédulos sin imposición. 
86. Y presentaron declaraciones de falsos testigos; por Allāh que nunca aceptaremos esa declaración.

87. Han mentido en todo lo que han dicho de nosotros, no es más que la mayor falsedad.

88. Fue el miedo a la muerte y a ser quemados lo que nos hizo convertirnos y repetir las palabras que nos hicieron decir, pero solo fueron palabras que no salían del corazón.

89. A pesar de todo, hemos seguido la religión del Profeta en todo momento, así como nuestra fe en que el único dios que es Allāh.

90. Y juramos por Allāh que no aceptaremos cambiar nuestra religión por aquella que utiliza la Trinidad.

91. Y si dicen que hemos aceptado su religión sin que nos hayan causado ningún mal y sin obligarnos a ello,

92. Pregunta a Güéjar por sus habitantes, cómo fueron apresados y aniquilados sufriendo humillación y desdicha.

93. Y pregunta a Velefique y lo que pasó a su gente, que fueron despedazados a espada después de haber soportado una gran angustia.

94. Y pregunta a los habitantes de Minerva que fueron descuartizados por la espada y lo mismo hicieron con la gente de las Alpujarras.

95. Y a los de Andarax los quemaron a todos en su mezquita y quedaron convertidos en carbón.

96. ¡Aquí estamos! nuestro Señor, nos quejamos ante vos de todo lo que hemos sufrido y lo peor de todo es la separación.

97. Tal vez ¿no hubiera sido mejor dejarnos con nuestra religión y nuestras oraciones, como habían prometido antes de romper el pacto?

98. Y si no, que nos hubiesen dejado irnos a todos de su tierra, llevándonos nuestras pertenencias al Norte de África donde está la tierra de nuestros queridos hermanos.

99. Pues para nosotros era mejor emigrar a quedar en la incredulidad, con honor, pero sin religión.

100. Lo que pedimos de vuestra generosidad, ique nuestras necesidades sean por vos satisfechas!

101. De vos esperamos el fin de nuestra angustia, de nuestra desgracia y de la humillación que estamos sufriendo.

102. Alabado sea Allāh. Vos sois nuestro mejor rey y vuestra gloria está por encima de todas las glorias.

103. Pedimos a nuestro Señor que prolongue vuestra vida en grandiosidad, en gloria, en alegría y en prosperidad.

104. Y que la paz llene vuestros dominios, y que la victoria os acompañe sobre vuestros enemigos, y que Allāh os aumente de tropas, de riquezas y de magnificencia.

105. Por ultimo, que la paz de Allāh unida a su clemencia sean sobre vosotros todos los días y a toda hora. 
A continuación presentamos el texto en árabe:

أخص به مولاي خير خليفة

ومن ألبس الكفار ثوب المذلة

وأيده بالنصر في كل وجهة

قسطنطينية أكرم بها من مدينة

بجن وأتراك من أهل الرعاية

وزادكم ملكاً على كل ملة

من العلماء الأكرمين الأجلة

ومن كان ذا رأي من أهل المشورة

بأندلس بالغرب في أرض غربة

وبحرّ عميق ذو ظلام ولجة

مصاب عظيم يالها من مصيبة

شيوبهم بالنتف من بعد عزة

على جملة الأعلاج من بعدة سترة

يسوقهم اللَّبَّاط قهراً لخلوة

على أكل خنزير ولحم لجيفة

وندعوا لكم بالخير في كل ساعة

وعافاكم من كل سوء ومحنة

وأسكنكم دار الرضـا والكرامة
1. سلام كريم دائم متجدد

2. سلام على مولاي ذي المجد والعلا

3. سلام على من وسع الله ملكه

4. سلام على مولاي من دار ملكه

5. سلام على من زين الله ملكه

6. سلام عليكم شرف الله قدركم

7. سلام على القاضي ومن كان منّله

8. سلام على أهل الديانة والتقى

9. سلام عليكم من عبيد تخلفوا

10. أحاط بهم بحرّ من الروم زاخر

11. سلام عليكم من عبيد أصابهم

12. سلام عليكم من شيوخ تمزقت

13. سلام عليكم من وجوه تكشفت

14. سلام عليكم من بنات عوائق

15. سلام عليكم من عجائز أكرهت

16. نقبل نحن الكل أرض بساطكم

17. أدام الإله ملككم وحياتكم

18. وأيدكم بالنصر والظفر بالعدا 
من الضر والبلوى وعظم الرزية

ظلمنا وعوملنا بكل قبيحة

نُقاتل عمال الصليب بنية

بقتل وأسر ثم جوع وقلة

بسيل عظيم جملة بعد جملة

بجد وعزم من خيول وعدة

فنقتل فيها فرقة بعد فرقة

فرساننا في حال نقص وقلة

ومالوا علينا بلدة بعد بلدة

تهدم أسوار البلاد المنيعة

شهوراً وأياماً بجد وعزمة

ولم نر من إخواننا من إغاثة

أطعناهم بالكره خوف الفضيحة

من أن يؤسروا أو يقتلوا شر قتلة

الدجن من أهل البلاد القديمة

ولانتركن شيئاً من أمر الشريعة

بما شاء من مال إلى أرض عدوة

تزيد على الخمسين شرطاً بخمسة

لكم ماشرطتم كاملاً بالزيادة
19. شكونا لكم مولاي ماقد أصابنا

20. غدرنا ونصرنا وبدل ديننا

21. وكنا على دين النبي محمد

22. ونلقي أموراً في الجهاد عظيمة

23. فجاءت علينا الروم من كل جانب

24. ومالوا علينا كالجراد بجمعهم

25. فكنا بطول الدهر نلقي جموعهم

26. وفرسانها تزداد في كل ساعة

27. فلما ضعفنا خيموا في بلادنا

28. وجاؤوا بأنفاط عظام كثيرة

29. وشدوا عليها الحصار بقوة

30. فلما تفانت خيلنا ورجالنا

31. وقلت لنا الأقوات واشتّ حالنا

32. وخوفاً على أبنائنا وبناتتا

33. على أن نكون متل من كان قبلنا

34. ونبقى على آذاننا وصلاتتا

35. ومن شاء منا البحر جاز مؤمنا

36. إلى غير ذاك من شروطٍ كثيرة

37. فقال لنا سلطانهم وكبيرهم 
و قال لنا هذا أماني و ذمتي

كما كنتم من قبل دون أذية

بدا غدرهم فينا بنقض العزيمة

ونصرنا كرهاً بعنف وسطوة

وخلطها بالزبل أو بالنجاسة

ففي النار ألقوه بهزءة وحقرة

ولا مصحفاً يخلى به للقراءة

ففي النار يلقوه كل حالة

يعاقبه اللباط شر العقوبة

ويجعله في السجن في سوء حالة

بأكل وشرب مرة بعد مرة

ولانذكرنه في رخاء وشدة

فأدركهم منهم أليم المضرة
بضرب وتغريم وسجن وذلة

38. وأبدى لنا كُنبا بعهد وموثق

39. فكونوا على أموالكم ودياركم

40. فلما دخلنا تحث عقد ذمامهم

41. وخان عهوداً كان قد غرنا بها

42. وأحرق ما كانت لنا من مصاحف

43. كل كتاب كان في أمر ديننا

44. ولم يتركوا فيها كتاباً لمسلم

45. ومن صام أو صلى و يعلم حاله

46. ومن لم يجئ منا لموضع كفرهم

47. ويلطم خديه ويأخذ ماله

48. وفي رمضان يفسدون صيامنا

48. وقد أمرونا أن نسب نبينا

50. وقد سمعوا قوماً يغنون باسمه

51. وعاقبهم حكامهم وولاتهم

52. ومن جاءه الموت ولم يحضر الذي بذكرهم لم يدفنوه بحيلة

53. ويترك في زبل طريجاً مجدلاً منل حمار ميت أو بهيمة

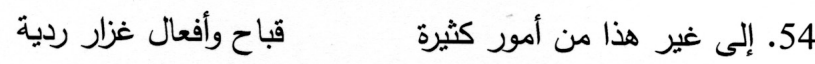

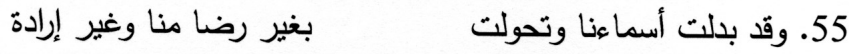

56. فآها على تبديل دين محمد البين البرية 


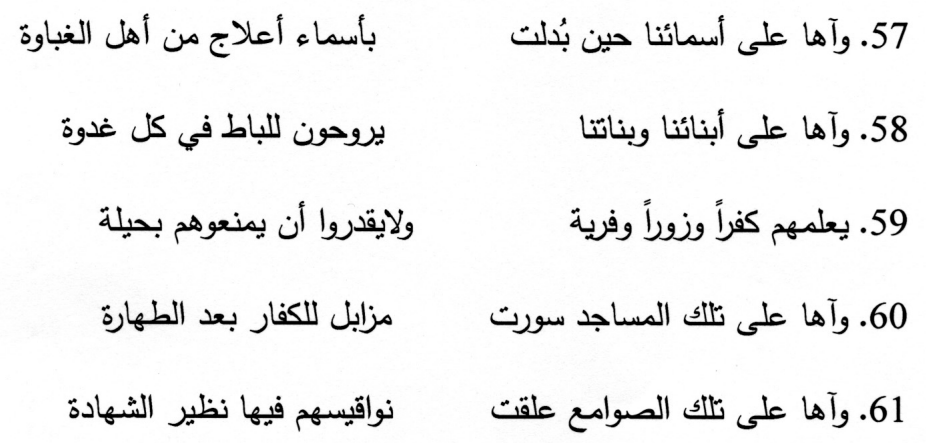

62. وآها على تلك البلاد وحسنها لقد أظلمت بالكفر أعظم ظلمة

63. وصارت لعباد الصليب معاقلاً وقد أمنوا فيها وقوع الاغارة

64. وصرنا عبيداً لا أسارى فنفتدي ولا مسلمين منطقهم بالثهادة

65. فلو أبصرت عينالك ماصار حالنا إليه لجادت بالدموع الغزيرة

66. فيا ويلنا، يابؤس ماقد أصابنا الضر والبلوى وثوب المذلة

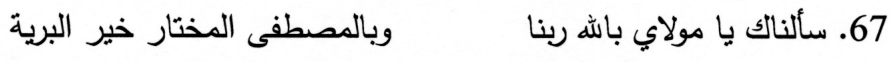

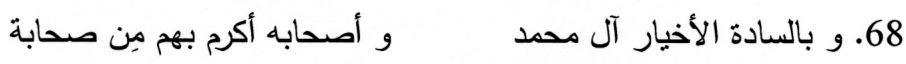

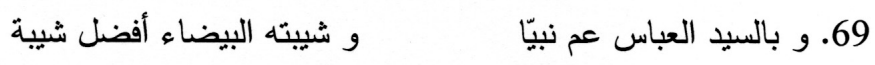

70. و بالصالحين العارفين بربهم ل ولي فاضل ذي كرامة

71. عسى تتظروا فينا وفيما أصابنا لعل إله العرش يأني برحمة

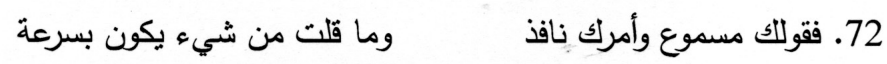

73. ودين النصارى أصله تحت حكمم ومن ثم يأتيهم إلى كل كورة

74. فباله بامولاي منوا بفضلكم بلينا برأي أو بحجة

75. فأنتم أولوا الأفضال والمجد والعلا وغوث عباد الله في كل آفة 
76. فسل بابهم أعني المقيم برومة بماذا أجازوا الغدر بعد الأمانة ؟

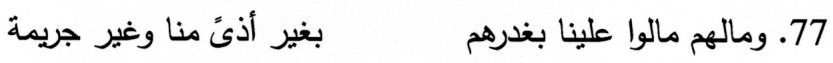

78. وجنسهم المغلوب في حفظ ديننا وأمن ملوك ذي وفاء أجلة

79. ولم يخرجوا من دينهم وديارهم ولانالهم غدر ولاهثك حرمة

80. ومن يعط عهداً ثم يغدر بعهده فذاك حرام الفعل في كل ملة

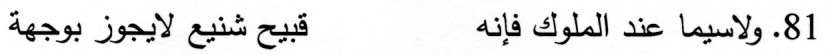

82. وقد بلغ المكتوب منكم إليهم لم يعلموا منه جميعاً بكلمة

83. ومازادهم إلا أعتداء وجرأة علينا وإقداماً بكل مساءة

84. وقد بلغت ارسال مصر إليهم ومانالهم غدر ولاهنك حرمة

85. وقالوا لتلالك الرسل عنا بأننا رضينا بدين الكفر من غير قهرة

86. وساقوا عقود الزور ممن أطاعهر ووالله مانرضى بنلك الشهادة

87. لقد كذبوا في قولهم وكلامهم علينا بهذا القول أكبر فرية

88. ولكن خوف القتل والحرق ردنا نقول كما قالوه من غير نية

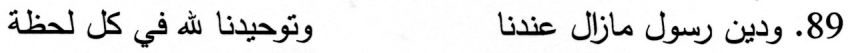

90. وواله مانرضى بتبديل ديننا ولا بالذي قالوا من أمر الثلاثة

91. وإن زعموا أنا رضينا بدينهم بغير أذى منهم لنا ومساءة

92. فسل وحرا عن أهلها كيف أصبحوا أسارى وقتلى تحت ذل ومهنة

93. وسل بلفيقاً عن قضية أمرها لقد مزقوا بالسيف من بعد حسرة

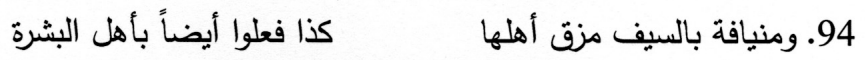




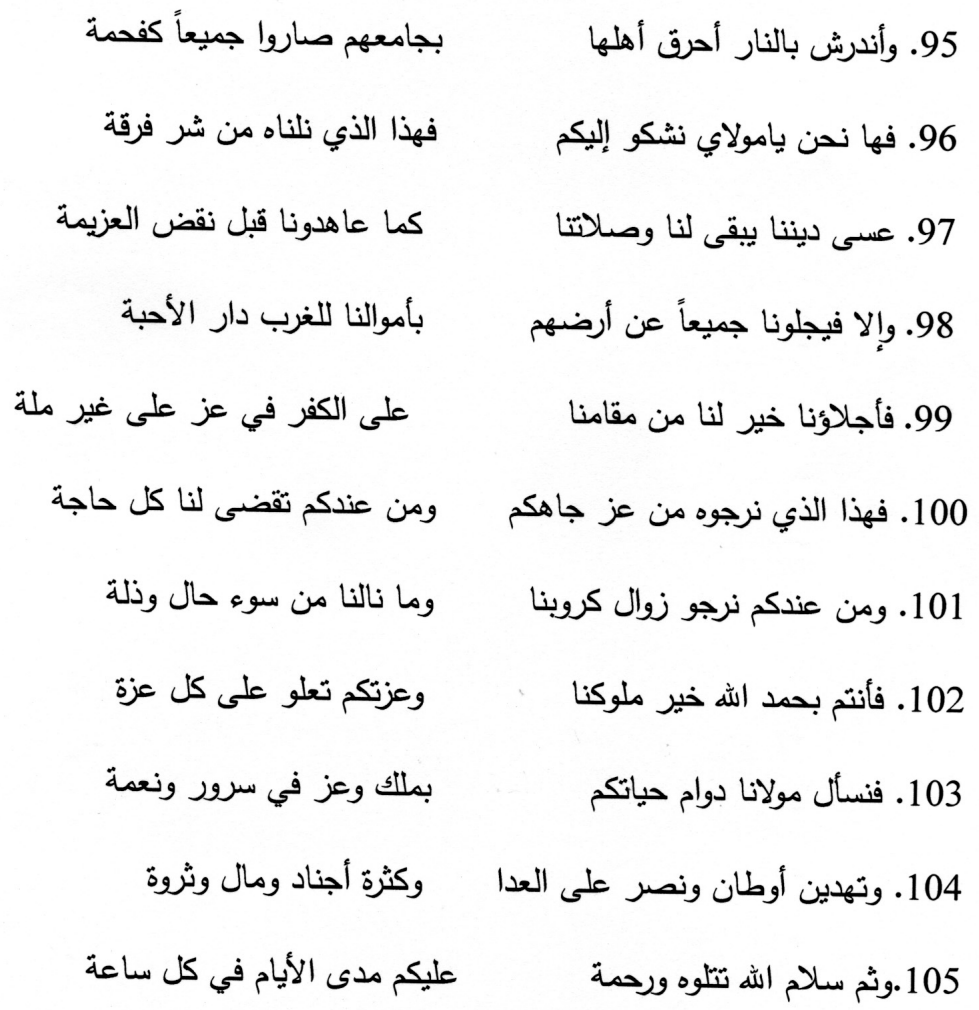

\section{RESUMEN}

Traducción del árabe y comentario de la casida dirigida por unos moriscos de Granada a comienzos del siglo XVI al sultán otomano Bayazid II, tal y

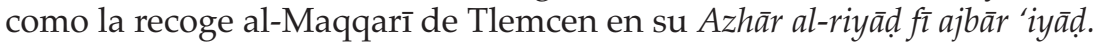

Palabras clave: moriscos, Granada, Casida, Bayazid II.

\section{Abstract}

Arabic translation and commentary of the qasīdah adressed by some moriscos from Granada to the Ottoman Sultan Bayazid II in the early sixteenth

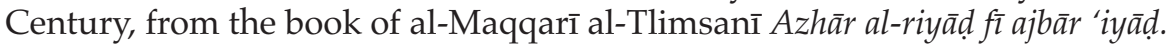

Key words: Moriscos, Granada, Qasīdah, Bayazid II. 